\title{
Reading Strategies and Reading Fluency: A Case Study of Reading in First or Second Language
}

\author{
Najmeh Barzegar \\ English Dept., Yazd University, Yazd, Iran \\ Ali. M. Fazilatfar \\ English Dept., Yazd University, Yazd, Iran
}

\begin{abstract}
The ability to read in second or foreign language (L2/FL) is a vital skill for academic and autonomous language learning. This study investigates the reading performance of two TEFL students from different language backgrounds on two English texts and their equivalent Persian translations comparing their reading rate and comprehension in $\mathrm{L1}$ and $\mathrm{L2}$. A combination of think-aloud protocol, interview and observation methods was used in order to figure out the reading strategies used by each participant in the process of reading and comprehending each text. First, participants were asked to model the steps of their thinking when reading the same text and to discuss what strategies and process they went through while interacting with the passage. Then, they were asked to respond some questions at the end of each reading passage. Last, an interview about their reading experiences and strategies is conducted. Findings of collected data from multiple sources were examined in the sense that the overall extracted themes were triangulated. The data were analyzed based on the Uso-Juan, Esther and Alicia Martinez-Flor (2006) framework for key reading strategies. The result showed that there is a positive relationship between reading fluency and reading comprehension. The most effective strategies employed by each participant were also reported. Through critically and analytically reflecting on differences between $\mathrm{L1}$ and $\mathrm{L} 2$ reading, language learners can learn how to read so as to get the most out of their academic materials.
\end{abstract}

Index Terms - first language reading, reading comprehension, reading fluency, reading strategies, second language reading

\section{INTRODUCTION}

Reading is regarded as a basic skill for second or foreign language academic learners by which they can develop independent learning of another language. Furthermore, there are many technical terms and more complex sentences in reading academic texts, which provide additional information. Many college students are challenged with their study dealing with learning problems for which they are not well-equipped with effective strategies to cope with. Reading is a complex activity that is influenced by many factors such as learning opportunities, motivation, prior knowledge, reading skills, cultural or language differences. Readers have various purposes and they often vary in the cognitive processes, knowledge, resources as well as the amount of emphasis given to these processes and resources. Some differences exist between first-language (L1) and second-language (L2) reading contexts as well as readers which can be linguistic and processing differences, individual and experiential differences or socio-cultural and institutional differences (Grabe and Stoller, 2018). Several studies have examined the role of word recognition in L2 reading. For instance, Favreau and Segalowitz (1983) demonstrated that differences in L2 reading fluency can be due to differential levels of automaticity in word recognition.

How students develop reading in English as a foreign or second language is studied in some research in second language learning. Previous research has shown that first and second language learners use similar strategies while reading (Gass \& Selinker, 2001). To decode and comprehend reading passages, L1 and L2 language learners may utilize their knowledge of vocabulary, sounds, meaning, language and textual structure as well as their prior knowledge (Bernhardt, 2000). Some other researchers claimed that there are some differences such as background knowledge and second language proficiency (Gass \& Selinker, 2001). L2 learners must develop their linguistic knowledge tackling the transfer effects and using first and second language resources when they learn to read in another language. (Grabe \& Stoller, 2002). Therefore, learning to read in an L2 for adults is not an easy task especially when they are from different linguistic, educational and cultural backgrounds. Some learners may develop second language faster than other learners due to many factors that affect acquiring a language such as individual goals (e.g. academic education, careers and employment, etc.), the context of language learning (e.g. learning atmosphere, informal and formal contexts, etc.), language instructions and language proficiency.

Good readers have the ability to make generalization, work readily with abstract ideas and analyze relationships. They utilize their prior experience and topical knowledge with text information, make use of higher level thinking skills and adopt a variety of strategies for reading and reading comprehension when they are reading. Gifted and fluent readers reread, infer, predict, analyze, evaluate and incorporate personal interpretation of the content of what they have 
read more than a normal reader which may lead to having more control over their process of reading (Fehrenbach, 1994).

The concept of metacognition refers to the learners' knowledge about knowledge (Sternberg, 1984) or awareness of, or control over one's cognitive processes in the cognitive psychology (Flavell, 1979). Learners who actively plan and manage to employ effective strategies and evaluate the effectiveness of different strategies used to perform a task (Brown, 1982; Jacobs \& Paris, 1987). Metacognitive strategies make learners engage in the conscious control over selecting, planning, regulating and evaluating their activities according to the given situation. In reading comprehension, readers are considered to be proficient when they have the ability to control and monitor their reading strategies while reading and processing the text and the knowledge to adopt various strategies or to remedy their comprehension where confusion occurs (Wenden, 1998).

In the past few years, reading fluency has given importance which includes both word recognition fluency and accuracy requiring automaticity in processing extended text, appropriate use of prosodic and syntactic structures and a long time to develop (Juan, E. U., \& Flor, A. M, 2006).

In L2 settings, improved word recognition fluency and extended exposure to print materials or extensive reading have been proven to be independent predictors of reading ability and reading comprehension over long periods of time (Grabe, 2009; Krashen, 2004; Stanovich, 2000).

\section{A. Reading Speed}

Reading speed or generally the rate of word recognition which is known as one of the indicators of reading fluency refers to the total number of words recognized by a person per minute. Researchers have suggested that a skilled reader normally reads in first language at around 250-300 wpm and makes about 90 fixations per 100 words (Carver 1982). It is suggested that for a second language learner who is reading a text containing only familiar words to him/her should be around $250 \mathrm{wpm}$ (Nation, 2009). But some researchers have proven that reading in second/foreign language is even slower than reading in first language.

Numerous studies have investigated the components of comprehension in reading which can be divided into reading comprehension and linguistic comprehension (Dombey, 2009). Linguistic comprehension deals with using the knowledge of vocabulary to understand the text presented orally and reading comprehension deals with using vocabulary knowledge relying on the written information comes to the eye. Some researchers have suggested that comprehension can be an indicator of fluency in silent reading including (Grabe, 2004; Nation, 2005; Yamashita \& Ichikawa, 2010). Both fast reading and simultaneously comprehending the text are necessary for a fluent reader.

In many reading fluency instructions, the students are asked to report their speed in reading words per minute as well as to answer the accompanying questions about their reading comprehension in order to obtain information about learners' progress in reading speed and at the same time their comprehension level (Quinn \& Nation, 2007).

There is a controversy in the past research associated with the relationship between comprehension and reading speed. In some previous studies (Grabe, 2010; Perfetti, Landi, \& Oakhill, 2005; Stanovich, 2000), a strong relationship between comprehension and reading speed in L1 reading has been suggested. On one hand, Nicholson \& Tan (1999) and Levy et al. (1997) found that increasing reading speed facilitates comprehension. On the other hand, other researchers have proposed a weak relationship between fluency skills and reading comprehension level (Carver, 1982; Kuhn \& Stahl, 2003).

\section{B. Reading Differences in L1 and L2 Settings}

There are many ways in which reading in L1 setting can differ from reading in L2 setting. The focus of these differences may rely on some linguistic resources that a reader brings to the situation in which text comprehension takes place. The differences can be:

- Second language learners have a limited knowledge of vocabulary, grammar and text structure when they begin reading and their linguistic resources of second language are smaller than those of first language learners.

- Second language learners have less exposure and then less practice and experience in second language reading.

- Second language learners have distinctive cognitive device involving two language systems such as bilingual lexicon and joint strategic planning that resulted in different reading process from first language learners (Kern, 1994; Koda, 2005).

- Second language learners deal with a range of transfer effects that may either facilitate or inhibit L2 reading process including strategies, goals and expectations. (Dressler \& Kamil, 2006; Koda, 2005)

- Second language learners' knowledge of world may vary across L1 and L2 setting and they make use of a compilation of different background knowledge.

- Second language learners may encounter with L2 texts that appear unfamiliar to them requiring distinct cultural or social background knowledge

The aim of this case study is to making comparison between two readers, one of them is a second language learner with Persian as her L1 and the other is an early simultaneous bilingual with Persian and English as her L1, in reading comprehension of materials where the main focus is not on learning English. They must utilize the study strategies wisely and appropriately, they must be able to monitor their comprehension while reading and they must apply 
alternative strategies when they realize that they fail to understand the text. Therefore, these research questions are to be answered:

- To some extent two readers participating in the research use different strategies while reading in English?

- To some extent two readers participating in the research use different strategies while reading in Persian?

- Is there any difference between two readers in their reading fluency?

\section{METHODOLOGY}

Creswell (1998) suggests that a key decision point in a qualitative study is the purposeful selection of participants. The purpose of this inquiry is to compare reading process followed by two participants from different language background in order to tap the reading strategies used by them.

So, their profiles are detailed as follows:

Profile of Student 1: An English student who is 30 years old and proficient enough in the foreign language to search for her reading strategies (Persian as L1 and English as FL). She is pursuing her master's degree in TEFL in Yazd University.

Profile of Student 2: A simultaneous bilingual who is in her late twenties (originally from India). After she obtained her bachelor's degree in India, she taught English in some institutions in Iran and decided to further her education. She has completed her master degree in TEFL at Allame Tabatabi's University.

\section{A. Reading Texts}

Two English texts and two Persian texts were used in this inquiry. The first reading passage was an academic text with approximately 636 words in length about humor and stress; the other passage including 867 word was a narrative text titled "Lucky Jim". Two Persian texts were translation versions of two English texts.

Both kind of narrative and expository texts were represented through these two passages in that a variety of reading strategies might be used when students interact with them.

\section{B. Think-aloud Protocol}

I employed a think aloud method to investigate how participants analyze the texts and what strategies they use while reading selected passages. This technique acts as a primary source of data to gather information about the thinking processes that readers deeply get involved in during reading.

First, I ascribed the data from the think aloud protocol. Next, I modified recursive issues and found common themes for metacognitive reading strategies. Then, I coded obtained data.

\section{Interview}

In order to elicit information about individual insights and experiences, a semi-structured interview was used. Participants discuss what they employed as the most frequently metacognitive strategies in reading given English texts.

\section{Data Collection}

Think-aloud protocol, observation and interview were the multiple sources of collecting data in this work. I followed the accompanying steps in gathering data. The participants meet up with each other for four 2-3 hour session. The sessions lasted over 2 weeks. Before the meeting, the participants were explained with the tasks they should perform. At the meeting, the researcher completed a questionnaire based on her observation followed by the think-aloud sessions. The researcher began by demonstration her thinking out loud using the short story. First after that, she asked the participants to model her steps of thinking while reading the same text.

Then, two students discussed what strategies and process they went through while interacting with the texts to make sense of them. Further giving their comments, participants read the English academic text on "Humor and Stress" to respond some questions at the end of each reading passage. Last, an interview about their reading experiences and strategies is conducted and the comments are transcribed on each student attempts to make sense of each selected texts.

\section{E. Data Analysis}

By using CCM method, in the analysis of think-aloud technique and interview, data were classified and coded in the process of the data collection.

Codes were modified according to reading strategies used by the participants in reading. The investigator reviewed the interview and think-aloud processes in the search for iterative and recurring issues related to the cognitive and metacognitive reading strategies. An analysis of content for every open-ended item is carried out to determine the most appropriate category for each response. Findings of collected data from multiple sources examined, specific themes were extracted in the sense that the overall themes were triangulated.

\section{F. Coding Scheme}

Over the last 30 years, many different first and second reading strategies have been identified. I mainly analyze the obtained data based on the following framework with three classifications of reading strategies adopted from (Juan, E. U., \& Flor, A. M., 2006). The first classification is known as metacognitive strategies (including purpose-oriented, 
comprehension monitoring, and strategies that focus on learning from text). The second classification is called cognitive strategies (including strategies for interacting with the author and the text, strategies involving different ways of reading, strategies for handling unknown words, and those making use of one's prior knowledge in some way), as well as social and affective strategies as the last category(including considering factors such as emotions and attitudes).

\section{G. Framework for Key Reading Strategies}

The key reading strategies (adapted from Grabe and Stoller 2002; Oxford 1990; Sarig 1993; Pressley 2000; Anderson 1991, 1999) framework of key reading strategies is adapted for comparing strategies used by two participants in this inquiry. (as cited by Uso-Juan, Esther and Alicia Martinez-Flor (2006), p. 305)

\section{RESULT}

\section{A. Reading Strategies}

The results reveal that there are three broad areas: a) the most frequently used strategies by two readers in reading L2 texts, b) the most effective strategies used by two students in reading L2, c) the development of metacognition in reading L2. To achieve the purpose of reading a text for better text understanding, the readers should develop strategic reading competence i.e. the ability to take control of own process of making sense of the text. In both L1 and L2, skilled readers use various strategies in their attempts to comprehend texts and identify the strategies they use, the most effective strategies they use and the way skilled readers use them is necessary for comprehending written texts.

The analysis of data for finding the most frequently used strategies by two readers in reading L2 texts, the most effective strategies used by two students in reading L2, the development of metacognition in reading L2 was conducted. The bilingual student used a much wider range of metacognitive strategies when reading English texts than the other student and there were some distinctions in the use of specific strategies when the two students were processing the same English texts.

The participants in this inquiry were using similar metacognitive strategies in reading the two types of Persian texts (Table 1).

TABLE I

STRATEgIES Used By Both STUDENTS In REAding PERSIAN TEXTS

\begin{tabular}{|l|}
\hline Strategies used by both students in reading Persian texts \\
\hline Evaluating the quality of the text \\
Evaluating information in terms of whether it leads to one's purpose \\
Deciding whether the text is relevant to one's purpose \\
Reflecting on how well objectives were met \\
Comparing information from one text with that of another \\
Making connections between a text and one's prior knowledge \\
Re-reading \\
Underlining or marking in text \\
Making notes about what one has read \\
Paraphrasing what the author said in order to remember it \\
\hline
\end{tabular}

Similar evidence of metacognition was seen while they engage in Persian reading tasks including: evaluating the quality of the text, evaluating information in terms of whether it leads to one's purpose, deciding whether the text is relevant to one's purpose, reflecting on how well objectives were met, summarizing what one has read, making connections between a text and one's prior knowledge, re-reading, underlining or marking in text, making notes about what one has read, paraphrasing what the author said in order to remember it. In addition, the ability to assess one's own reading practice also shows the participants' awareness of their own strengths or weaknesses as a reflection in reading skill.

The analysis showed that the most of the strategies fall into three categories:

8 purpose-oriented strategies, 5 comprehension-monitoring strategies, 3 repair strategies and 5 strategies that focus on learning from reading were employed more often by student1.

The transcript from the interview responses and think-aloud procedure indicated that the participant who had learnt English from childhood was more successful in implementing different types of strategies in reading across the two English text types including the metacognitive, cognitive and social and affective strategies.

The student who was learning English at university, stated that she memorize important points or key concepts in order to be able to comprehend the text. She tended to read the passage at word or sentence level, and she sometimes tried to translate the text into her first language for better comprehension of the idea that the author was trying to convey or reread the text if it was not primarily understood.

After assessing data obtained from think-aloud protocol against the two types of English texts, Student 2 was supposed to be more skillful and fluent reader than student1. She made fewer pauses while reading both texts in 
comparison with the other reader. She read them faster with fewer miscues as well. It may be due to the fact that when she was reading the passage, she processed most of the reading comprehension at the same time. That was observable that she read the text easily in such a way that fewer cognitive and more metacognitive reading strategies were needed to be used by her compared to the other participant.

Also, student 2 analyzed the texts in larger chunks of words and she commented on them more often than the other reader. It could be deduced from her reflections that she truly figured out the massage of the texts.

It was concluded that the most reading strategies used by her in reading the two types of English texts were strategies such as summarizing, critiquing the text, connecting one part of the text to another, reading selectively, deciding whether or not to read something, constructing mental images to represent the meanings expressed in text, making connections between a text and one's prior knowledge and reflecting on what has been learned from the text (Table 2).

Reflecting on the texts and summarizing are two abilities requiring the students to synthesize the presented massage in the higher-level thinking processes.

Making connection between important ideas from a text and giving attention to supporting ideas to form overall meaning of the reading text are fundamental in higher-level comprehension process in the view of Grabe and Stroller (2002).

Exploiting the prior knowledge to make association with the reading text for full comprehension is considered essential for both readers. The results also indicated that student 2 benefited from integration of textual information with her prior knowledge helping her to interact with the relevant topics better than student 1 . When reading in second language, student 1 was faced with some unfamiliar words; hence, she tried to look up the words meanings and to paraphrase all of the text into her own personal understandings.

TABLE II

STRATEGIES USED BY STUDENT 2 IN READING ENGLISH TEXTS

\begin{tabular}{|l|}
\hline Strategies used by student $\mathbf{2}$ in reading English texts \\
\hline Summarizing what one has read \\
Reminding oneself about the purpose for reading \\
Deciding whether a text is relevant to one's purpose \\
Reflecting on what has been learned from the text \\
Paraphrasing what the author said in order to remember it \\
Critiquing the author/text \\
Thinking how to use a text in the future \\
Interpreting the text \\
Making connections between a text and one's prior knowledge, paying attention to text structure \\
Constructing mental images to represent the meanings expressed in text \\
Skimming for a general idea \\
Scanning for specific information \\
Reading selectively \\
Deciding whether or not to read something \\
Ignoring certain texts or parts of a text \\
Thinking about what one already knows about a topic \\
Connecting one part of the text to another \\
Analyzing texts into the typical components and language of that genre \\
Rewarding oneself \\
Selecting what one wants to read
\end{tabular}

The data suggested that the most frequently-used strategies by student1 in reading English texts were strategies such as summarizing what one has read, evaluating one's understanding, identifying difficulties in understanding, re-reading, previewing a text, asking questions about the text, Looking for answers to questions about the text and paying attention to text structure (Table 3).

TABLE III.

STRATEGIES USED By STUDENT 1 IN READING ENGLISH TEXTS

\begin{tabular}{|l|}
\hline Strategies used by student $\mathbf{1}$ in reading English texts \\
\hline Evaluating one's understanding \\
Identifying difficulties in understanding \\
Re-reading \\
Slowing down and reading again \\
Previewing a text \\
Predicting the contents of the text \\
Asking questions about the text \\
Looking for answers to questions about the text \\
Using other information in the context to understand an unknown word \\
Analyzing the structure or parts of a word to understand it \\
Revising one's prior knowledge that is inconsistent with ideas in the text \\
Paying attention to text structure \\
Talking with others about what one reads \\
\hline
\end{tabular}


During the think aloud session giving information about student2, her reflection usually involved employing a lot of reading strategies to cope with the task demands and adjusting them to overcome the breakdown in comprehension. A set of effective strategies which were repeatedly used by the bilingual student in each text type to increase their comprehension of transactional text extracted from data obtained from the think aloud and interview analysis contains:

- Reflecting on how well objectives were met

- Predicting the contents of the text

- Thinking about what one already knows about a topic and revising one's prior knowledge that is inconsistent with ideas in the text, if convinced by information or arguments in the text

- Verifying whether one's guess about meaning fits the context and one's conceptual knowledge; then revising or seeking alternative explanations

- Evaluating and revising hypotheses that arose while reading

- Summarizing what one has read

- Making associations to ideas presented in a text based on prior knowledge

- Critiquing the text

- Encouraging oneself

\section{B. Reading Fluency}

One problem that English readers of other languages are encountered is that they slowly read in English as their foreign or second language (L2). Slow reading for many learners, especially ESOL postgraduate learners may cause limitation in their ability to meet the requirements of their courses and thus lack of the necessary time to read e.g. professional documentation, dissertation, etc.

The link between comprehension and speed in L2/FL reading has not been clearly demonstrated. In this study, student 2 read the expository English passage at around $216 \mathrm{wpm}$ and the read the narrative English passage at around $255 \mathrm{wpm}$. Student 1 read the expository English passage at around $127 \mathrm{wpm}$ and the narrative English passage at around $158 \mathrm{wpm}$. Also, student 2 read the expository Persian text at around $195 \mathrm{wpm}$ and the narrative Persian text at around 164 wpm. Student1 read the expository Persian text at around 174 wpm and the narrative Persian text at around 198 wpm. The findings are shown in Table 4.

TABLE IV.

AN EXAMPLE OF A TABLE

\begin{tabular}{|lllll|}
\hline Participants & Reading Speed & & & \\
\cline { 2 - 5 } & E/narrative & E/expository & P/expository & \\
\hline Student1 & 255 & 216 & 220 & 195 \\
Student2 & 158 & 127 & 198 & 174 \\
\hline
\end{tabular}

These findings indicate that the changes in reading speed from English to Persian texts differed for both students against expository and narrative passages. As Table 4 illustrates, reading speed for student 2 in reading English passages is similar to a native-like reading fluency. Student1 read much slower in both text types than the student2, although she read much faster in her first language showing the importance of the ability to read a text fluently as an essential component of reading skill. Reading rates were slower for expository rather than narrative tasks in both Persian and English language which can be due to being more cognitively demanding of expository texts in processing. Also, there was more change in reading fluency between two students for the English texts compared to the Persian texts. This result can explained by the fact that student 2 is a more fluent reader who is an additive bilingual in both Persian and English.

\section{CONCLUSION}

There are three differences between $\mathrm{L} 1$ and $\mathrm{L} 2$ readers and reading contexts

- Summarizing what one has read

- Individual and experiential differences

- Socio-cultural and institutional differences

What I have learned from the findings of this inquiry is that L2 students have developed metacognition in L2 reading by their experiences during a long period of study. At first of their study, they faced some difficulties in coping with challenging texts, then as graduating they were exposed to large amounts of reading and became capable of using appropriate strategies to increase their reading ability. In late bilingualism, L2 metacognitive reading strategies are developed incrementally through a time-consuming process, whereas they have already been developed for early bilinguals. The metacognitive strategies employed by student 2 in reading L2 texts were as a reminder of the metacognitive strategies used in reading L1 texts and those that are used by student 2 could be corresponded to metacognitive strategies used in reading $\mathrm{L} 2$ texts.

This study compared Persian and English reading speed and performance on two different reading text tasks (expository and narrative) for two students of English who differed in their English background and speaking community in which they had learned English language. 
The findings of the this research in accordance with previous studies demonstrated a noticeable difference between first and second language reading rate, also difference across various types of reading text (with various degree of complexity). Both participants were more fluent readers when they read in their first language.

Another explanation for the slow reading rate in English texts for student 1 is that she has not developed higher level skills of word processing and there is a gap between her knowledge system of word recognition and word automaticity. Another important finding resulted from comparisons between students' reading rate was the gap in their performance on pairs of tasks with less differentiation in Persian rather than in English texts. For instance, a much smaller difference between speed of reading for Persian expository and narrative tasks was seen (198 wpm compared to 174 wpm for student 1 and 220 wpm compared to 195 wpm for student2).

It can be discussed that student 1 in this inquiry reads at a consistently low reading rate in English and she is not able to adjust her processing level to the demand of task for reading texts in her second language to the same extent that she can for corresponding reading texts in her first language. This variation in reading rates for student1 in her first and second language reading suggests that Persian speaker participant has not yet been able to achieve her optimum reading rate in learning to read in her second language.

\section{APPENDIX. KEy READING STRATEGIES}

(adapted from Grabe and Stoller 2002; Oxford 1990; Sarig 1993; Pressley 2000; Anderson 1991, 1999) framework of key reading (as cited by Uso-Juan, Esther and Alicia Martinez-Flor (2006), p. 305)

\section{A.1. Metacognitive Strategies}

Purpose-oriented strategies:

- Planning what to do next, steps to take

- Reminding oneself about the purpose for reading

- Evaluating information in terms of whether it leads to one's purpose

- Deciding whether a text is relevant to one's purpose

- Comparing information from one text with that of another

- Reflecting on how well objectives were met

- Evaluating the quality of a text

- Checking the time one has available

Comprehension-monitoring strategies:

Assessing comprehension

- Evaluating one's understanding

- Identifying difficulties in understanding

- Summarizing what one has read

- Restating for oneself what one has read

- Reviewing a text after reading is completed

- Repair strategies

- Re-reading

- Slowing down and reading again

- Trying to pronounce words

Strategies that focus on learning from reading:

- Reflecting on what has been learned from the text

- Underlining or marking in text

- Thinking how to use a text in the future

- Making notes about what one has read

- Paraphrasing what the author said in order to remember it

\section{A.2. Metacognitive Strategies}

Strategies for interacting with author and text:

- Previewing a text

- Predicting the contents of the text

- Checking/confirming predictions

- Asking questions about the text

- Looking for answers to questions about the text

- Connecting one part of the text to another

- Critiquing the author

- Critiquing the text

- Evaluating and revising hypotheses that arose while reading

- Interpreting the text

- Making associations to ideas presented in a text based on prior knowledge 
- Constructing mental images to represent the meanings expressed in text

Strategies involving different ways of reading:

- Reading slowly

- Reading quickly

- Skimming for a general idea

- Scanning for specific information

- Re-reading

- Ignoring certain texts or parts of a text

- Reading out loud (and listening to how it sounds)

- Reading selectively/deciding whether or not to read something

- Reading ahead

Strategies for handling unknown words:

- Using other information in the context to understand an unknown word

- Skipping/ignoring an unknown word

- Waiting to see if more information is provided later

- Analyzing the structure or parts of a word in order to understand it

- Asking someone the meaning of a word

- Looking up a word in a dictionary

- Pronouncing a word

- Thinking about other related words that one already knows

- Thinking about cognates in the L1

- Translating a word/phrase into the L1

- Checking the spelling of a word

Strategies involving prior knowledge:

- World knowledge:

- Thinking about what one already knows about a topic

- Making connections between a text and one's prior knowledge

- Revising one's prior knowledge that is inconsistent with ideas in the text, if convinced by information or arguments in the text

- Knowledge of texts and text formats:

- Using discourse markers to identify relationships

- Connecting one part of a text to another

- Paying attention to text structure

- Verifying whether one's guess about meaning fits the context and one's conceptual knowledge; then revising or seeking alternative explanations

- Analyzing texts (e.g., stories, science reports) into the typical components and language of that genre (e.g., story grammar, steps/components of science experiments)

\section{A.3. Affective and Social Strategies}

Rewarding oneself

- Talking with others about what one reads

- Encouraging oneself

- Selecting what one wants to read

\section{REFERENCES}

[1] Bernhardt, E. (2000). Second-language reading as a case study of reading scholarship in the 20th century. In M. L. Kamil, P. B. Mosenthal, P. D. Pearson, \& R. Barr (Eds.), Handbook of reading research (Vol. 3, pp. 793-811). Mahwah, NJ: Erlbaum.

[2] Brown, A. L. (1982). Learning and development: The problems of compatibility, access and induction. Human development, 25(2), 89-115.

[3] Catron, R. M., \& Wingenbach, N. (1986). Developing the potential of the gifted reader. Theory into Practice, 25(2), 134-140.

[4] Carver, R. P. (1982). Optimal rate of reading prose. Reading Research Quarterly, 18, 56-88.

[5] Coda, K. (2005). Insights into second language reading: A cross-linguistic approach. New York, Cambridge University Press.

[6] Creswell, J. W., Hanson, W. E., Clark Plano, V. L., \& Morales, A. (2007). Qualitative research designs: Selection and implementation. The counseling psychologist, 35(2), 236-264.

[7] Dombey, H. (2009). The simple view of reading, Brighton, UK.: University of Brighton.

[8] Dressler, C., \& Kamil, M. L. (2006). First- and second-language literacy. In D. August \& T. Shanahan (Eds.), Developing literacy in second-language learners (pp. 197-238). Mahwah, NJ: Lawrence Erlbaum.

[9] Favreau, M., \& Segalowitz, N. S. (1983). Automatic and controlled processes in the first-and second-language reading of fluent bilinguals. Memory \& Cognition, 11(6), 565-574

[10] Fehrenbach, C.R. (1994). Cognitive style of gifted and average readers. Roeper Review, 16(4), 290-292.

[11] Flavell, J. H. (1979). Metacognition and cognitive monitoring: A new area of cognitive-developmental inquiry. American psychologist, 34(10), 906. 
[12] Fraser, C. A. (2007). Reading rate in L1 Mandarin Chinese and L2 English across five reading tasks. The Modern Language Journal, 91(3), 372-394.

[13] Gabryś-Barker, D., Piechurska-Kuciel, E., \& Zybert, J. (2013). Investigations in Teaching and Learning Languages, Studies in Honour of Hanna Komorowska. Berlin.

[14] Gass, S., \& Selinker, L. (2007). Second language acquisition: An introductory course. Mahwah, NJ: Lawrence Erlbaum Associates.

[15] Ghuma, M. (2011). The transferability of reading strategies between L1 (Arabic) and L2 (Doctoral dissertation, Durham University).

[16] Grabe, W. (2004). Research on teaching reading. Annual review of applied linguistics, 24, 44-69.

[17] Grabe, W. (2009). Reading in a second language: Moving from theory to practice. New York: Cambridge University Press.

[18] Grabe, W. and Jiang, X. (2018). First Language and Second Language Reading. In The TESOL Encyclopedia of English Language Teaching (eds J. I. Liontas, T. International Association and M. Delli Carpini).

[19] Grabe, W., \& Stoller, F. (2002). The nature of reading abilities. In W. Grabe \& F. Stoller (Eds.), Teaching and researching reading (pp. 9-39). London, UK: Pearson.

[20] Grabe, W., \& Stoller, F. L. (2002). Teaching and researching reading. Harlow, UK: Longman/Pearson Education Ltd.

[21] Jacobs, J. E., \& Paris, S. G. (1987). Children's metacognition about reading: Issues in definition, measurement, and instruction. Educational psychologist, 22(3-4), 255-278.

[22] Juan, E. U., \& Flor, A. M. (Eds.). (2006). Current trends in the development and teaching of the four language skills (Vol. 29). Berlin: Mouton de Gruyter.

[23] Kern, R. G. (1994). The role of mental translation in second language reading. Studies in second language acquisition, 16(4), 441-461.

[24] Krashen, S. D. (2004). The power of reading: Insights from the research: Insights from the research. Portsmouth: Heinemann and Westport, CN: Libraries Unlimited.

[25] Kuhn, M. R., \& Stahl, S. A. (2003). Fluency: A review of developmental and remedial practices. Journal of educational psychology, 95(1), 3-21.

[26] Levy, B. A., Abello, B., \& Lysynchuk, L. (1997). Transfer from word training to reading in context: Gains in reading fluency and comprehension. Learning Disability Quarterly, 20(3), 173-188.

[27] Nation, K. (2009). Reading comprehension and vocabulary. In R.K. Wagner, C. Schatschneider \& C. PhytianSence (Eds.), Beyond decoding. (pp. 176-194). New York: Guilford Press.

[28] Nicholson, T., \& Tan, A. (1999). Proficient word identification for comprehension. In G. Thompson \& T. Nicholson (Eds.), Learning to read: Beyond phonics and whole language (pp. 150-173). New York: Teachers College Press.

[29] Perfetti, C., Landi, N., \& Oakhill, J. (2005). The acquisition of reading comprehension skill. In M.J. Snowling \& C. Hulme (Eds.), The science of reading. Oxford: Blackwell Publishing.

[30] Quinn E, Nation P, Millett S. (2007). Asian and Pacific Speed Readings for ESL Learners. Wellington: English Language Institute Occasional Publication.

[31] Robinson, P., \& N. C. Ellis, (eds.). (2008). A handbook of cognitive linguistics and second language acquisition. London: Routledge.

[32] Shomdani, M. (2016). Exploing EFL learners in reading narrative texts: A case study at Iain Syekh Nurjati Cirebon (Doctoral dissertation, State Islamic Institute).

[33] Stanovich, K. E. (2000). Progress in understanding reading: Scientific foundations and new frontiers. New York: Guilford Press.

[34] Sternberg, R.J. (1984), "What should intelligence tests test? Implications of a triarchic theory of intelligence for intelligence testing", Educational Researcher, 13(1), 5-15.

[35] Walters, J. (2006). Methods of teaching inferring meaning from context. RELC Journal, 37(2), 176-190.

[36] Wenden, A. L. (1998). Metacognitive knowledge and language learning1. Applied linguistics, 19(4), 515-537.

[37] Yen, T. T. N. (2012). The effects of a speed reading course and speed transfer to other types of texts. RELC Journal, 43(1), 2337.

[38] Yamashita, J., \& Ichikawa, S. (2010). Examining reading fluency in a foreign language: Effects of text segmentation on L2 readers. Reading in a Foreign Language, 22(2), 263-283.

[39] Zhang, L. (2018). Metacognitive and Cognitive Strategy Use in Reading Comprehension. Singapore: Springer.

Najmeh Barzegar is M.A. holder of English language from Yazd University, Yazd, Iran. Her research interests include language teaching methodologies, interlanguage pragmatics and discourse analysis.

Ali. M. Fazilatfar (Corresponding Author) is currently an associate professor of applied linguistic at English Dept, Yazd University,Yazd, Iran. He has published several papers at International Journals and Conferences. His research interests include language teaching methodologies and teaching language skills. 